SCIENTIFIC LETTER

\title{
Importance of $\beta$ blockade in the treatment of advanced heart failure
}

\author{
R S Gardner, W Martin, R Carter, T A McDonagh
}

Heart 2003;89:1442-1444

S evere chronic heart failure (CHF) can still be associated with an annual mortality of up to $51 \% .^{1}$ Over the last seven years, $\beta$ blockers have been conclusively shown to improve both morbidity and mortality in heart failure, even in its advanced stages. ${ }^{2}{ }^{3}$ However, a recent report suggests $\beta$ blocker use in CHF is still not widespread. ${ }^{4}$ This may be due to non-specialist care, perceived or actual difficulty establishing patients on this treatment, or perhaps the recollection of old teachings on the dangers of $\beta$ blockade in heart failure.

This study describes the experience of $\beta$ blockade and its effects in patients with CHF caused by severe left ventricular systolic dysfunction (LVSD), and seeks to extend the importance of the clinical trial data into the real world.

\section{METHODS}

We retrospectively studied the effects of baseline $\beta$ blocker use in 128 consecutive patients with advanced heart failure on their referral to the Scottish Cardiopulmonary Transplant Unit for cardiac transplantation (CTx) assessment between April 2001 and August 2002. Treatment on initial assessment was documented and subsequently optimised. Patients had their left ventricular ejection fraction (LVEF) measured by radionuclide ventriculography and, where possible, a progressive exercise test to quantify their peak oxygen uptake $\left(\dot{V}_{2}\right)$. A baseline heart failure survival score (HFSS) was calculated for each patient. The primary end point was all cause mortality and the secondary end point was all cause mortality or urgent transplantation. Urgent transplantation is considered in suitable inotrope dependent patients with end stage heart failure who have an anticipated life expectancy of less than one week. Patients were followed up for a median of 376 days (range 1-599 days).

\section{RESULTS}

As would be expected in a CTx assessment population, the overall mean age was relatively young (mean (SD) 50.8 (10.2) years), and $85 \%$ of patients in this study had heart failure in New York Heart Association (NYHA) classes III or IV. On referral, $93 \%$ of patients were treated with an angiotensin converting enzyme (ACE) inhibitor or angiotensin receptor blocker (ARB). Only $68 \%$ of patients were treated with a $\beta$ blocker and $60 \%$ with spironolactone. The clinical and demographic features of the study group at baseline are given in table 1 , stratified according to baseline $\beta$ blocker treatment.

Of the 128 patients studied, 19 (14.8\%) died, and 23 ( $18.0 \%)$ either died or required urgent transplantation. A further 14 patients $(10.9 \%)$ were transplanted during the study, but these subjects were considered survivors. Of the 87 (68\%) patients treated with a $\beta$ blocker at baseline, 52\% were taking carvedilol, 40\% bisoprolol, and others accounted for the remaining $8 \%$. Patients were more likely to be treated with a $\beta$ blocker if they were male, of higher weight, or in lower NYHA class. Those on a $\beta$ blocker were also more likely to have a lower heart rate, a higher systolic blood pressure, and be on ACE inhibitor treatment. However, there were no significant differences in the baseline LVEF, peak $\dot{\mathrm{V}}_{2}$ or HFSS of patients treated with or without a $\beta$ blocker.

Kaplan-Meier survival analysis stratified for baseline $\beta$ blocker use is shown in fig 1 . Patients not treated with a $\beta$ blocker were five times more likely to die $(31.7 \% \vee 5.9 \%$, $\mathrm{p}<0.001)$ than those who had already been established on any dose of a $\beta$ blocker, despite their treatment being commenced and optimised after referral. In a Cox proportional hazards model, the only independent predictors of mortality were not being treated with a $\beta$ blocker $\left(\chi^{2}=4.4\right.$, $\mathrm{p}=0.037$ ) and a $\mathrm{N}$ terminal pro-brain natriuretic peptide (NT-proBNP) above the median $\left(\chi^{2}=13.3, \mathrm{p}=0.0003\right)$. Both were better predictors of prognosis than the LVEF or peak $\dot{\mathrm{V}}_{2}$, neither of which reached independent significance.

Only $25.8 \%$ of patients referred for CTx assessment were treated with an optimal dose of $\beta$ blocker (carvedilol $25 \mathrm{mg}$ twice daily, or equivalent); $43.8 \%$ of survivors were on an optimum dose of $\beta$ blocker, compared with $13.9 \%$ in those who died $(p=0.003)$. Patients not receiving an optimal dose of $\beta$ blocker were 10 times more likely to die $(31.7 \%$ v 3\% mortality, $\mathrm{p}<0.001)$ and 12 times more likely to die or require urgent transplantation $(36.6 \% v 3 \%, \mathrm{p}<0.001)$ than those on an optimal dose of $\beta$ blocker.

Patients treated with a $\beta$ blocker at baseline had a significantly lower median NT-proBNP concentration than those patients not treated with a $\beta$ blocker $(1024 \mathrm{pg} / \mathrm{ml}$ (interquartile range 413-2430 pg/ml) v 2103 pg/ml (1117$9124 \mathrm{pg} / \mathrm{ml}), \mathrm{p}<0.001)$. Those patients on optimal doses of $\beta$ blocker had a lower median NT-proBNP concentration than those on smaller (initiating) doses of $\beta$ blocker $(974 \mathrm{pg} / \mathrm{ml}$ (range $372-2534 \mathrm{pg} / \mathrm{ml}$ ) $v 2933 \mathrm{pg} / \mathrm{ml}$ (1336-8649 pg/ml), $\mathrm{p}=0.045)$. There was a significant correlation between $\beta$ blocker dose and NT-proBNP concentration $(r=-0.30$, $\mathrm{p}<0.001)$.

\section{DISCUSSION}

The management of CHF has changed dramatically over the last two decades. In clinical trials $\beta$ blockers have been shown to lead to long term improvement in patients with CHF, in terms of reduced hospitalisation, improved left ventricular function, slowing of heart failure progression, and increased life expectancy. ${ }^{2}$ Although initially there can be some clinical deterioration, even these patients can gain long term benefit. Long term treatment with $\beta$ blockers has also been shown to reduce the need for cardiac transplantation. ${ }^{5}$ More recently, $\beta$ blockers have also been shown to confer improvement in

\footnotetext{
Abbreviations: $A C E$, angiotensin converting enzyme; $A R B$, angiotensin receptor blocker; CHF, chronic heart failure; CTx, cardiac transplantation; HFSS, heart failure survival score; LVEF, left ventricular ejection fraction; LVSD, left ventricular systolic dysfunction; NT-proBNP, $\mathrm{N}$ terminal pro-brain natriuretic peptide; NYHA, New York Heart Association; $\dot{\mathrm{V}} \mathrm{O}_{2}$, oxygen uptake
} 
Table 1 Demographics of 128 patients with advanced heart failure according to baseline $\beta$ blocker treatment

\begin{tabular}{|c|c|c|c|}
\hline Characteristic & On $\beta$ blocker & Not on $\beta$ blocker & P Value \\
\hline $\begin{array}{l}\text { Age (years) } \\
\text { Male sex (\%) } \\
\text { Weight (kg) } \\
\text { NYHA class } \\
\text { IHD (\%) } \\
\text { Atrial fibrillation (\%) } \\
\text { Heart rate (beats/min) } \\
\text { Systolic BP (mm Hg) } \\
\text { QRS (ms) } \\
\text { LVEF (\%) } \\
\text { Peak VO }{ }_{2}(\mathrm{ml} / \mathrm{kg} / \mathrm{min}) \\
\text { HFSS* } \\
\text { Serum sodium } \\
\text { Serum creatinine } \\
\text { NT-proBNP* (pg/ml) } \\
\text { ACE/ARB use (\%) } \\
\text { Spironolactone (\%) } \\
\text { Digoxin (\%) } \\
\text { Diuretic dose (mg) }\end{array}$ & $\begin{array}{l}51.2(9.5) \\
88.2 \\
90.0(15.7) \\
2.9(0.5) \\
46(55 \%) \\
12(15 \%) \\
72.7(16.0) \\
112.2(18.3) \\
130.4(33.1) \\
15.4(6.9) \\
11.9(3.5) \\
7.72(7.15-8.31) \\
139.2(3.5) \\
128.7(31.7) \\
1024(413-2430) \\
82(95 \%) \\
52(61 \%) \\
38(45 \%) \\
109.4(83.1)\end{array}$ & $\begin{array}{l}50.0(11.8) \\
73.2 \\
77.6(15.9) \\
3.3(0.6) \\
16(39 \%) \\
9(22 \%) \\
81.6(13.6) \\
105.1(16.7) \\
135.3(43.1) \\
13.4(7.5) \\
10.9(3.3) \\
7.43(6.33-8.05) \\
137.9(3.3) \\
120.4(39.1) \\
2103(1117-9124) \\
33(81 \%) \\
23(56 \%) \\
22(54 \%) \\
129.3(77.1)\end{array}$ & $\begin{array}{l}\text { NS } \\
0.03 \\
<0.001 \\
0.001 \\
\text { NS } \\
\text { NS } \\
0.003 \\
0.04 \\
\text { NS } \\
\text { NS } \\
\text { NS } \\
0.08 \\
0.05 \\
\text { NS } \\
<0.001 \\
0.008 \\
\text { NS } \\
\text { NS } \\
\text { NS }\end{array}$ \\
\hline \multicolumn{4}{|c|}{$\begin{array}{l}\text { Values are expressed as mean (SD) or \%, except non-normally distributed variables }{ }^{*} \text { which are expressed as the } \\
\text { median (interquartile range). Diuretic dose is expressed as a frusemide (furosemide) equivalent dose. } \\
\text { ACE/ARB, angiotensin converting enzyme inhibitor/angiotensin receptor blocker; BP, blood pressure; HFSS, hear } \\
\text { failure survival score; IHD, ischaemic heart disease; } \mathrm{NEF} \text {, leff ventricular ejection fraction; NS, non-significant; } \mathrm{NT} \text { - } \\
\text { proBNP, } \mathrm{N} \text { terminal pro-brain natriuretic peptide; } \mathrm{NYHA} \text {, New York Heart Association; Peak } \mathrm{V}_{2} \text {, peak oxygen } \\
\text { uptake. }\end{array}$} \\
\hline
\end{tabular}
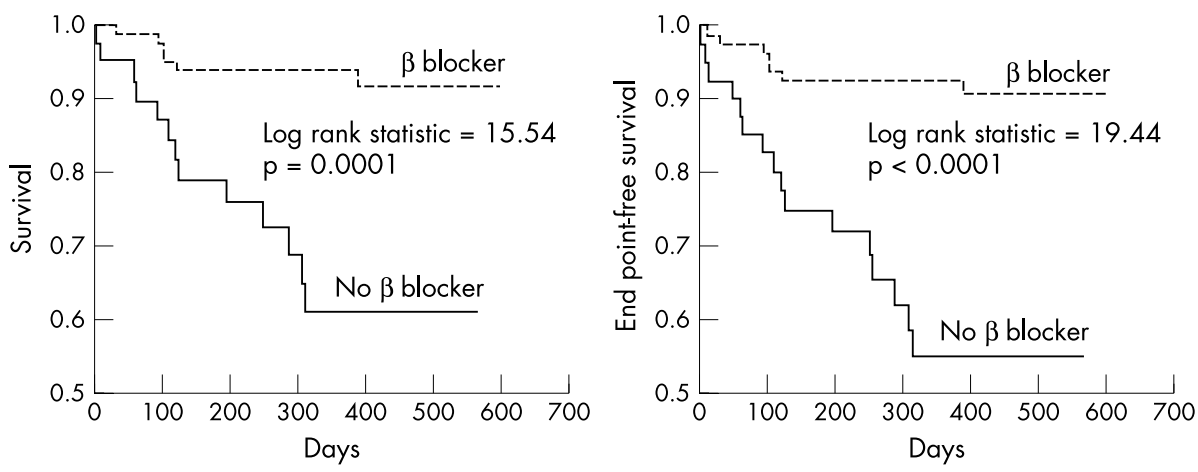

Figure 1 Kaplan-Meier survival curves for patients receiving (dashed line) or not receiving (solid line) a $\beta$ blocker at baseline against all cause mortality and the combined end point of death or urgent transplantation.

patients with severe CHF. ${ }^{3}$ In that study, patients in the placebo arm had a mean LVEF of $19.8(4.0) \%$. In our study, however, the mean LVEF of those not on a $\beta$ blocker was 13.4 (7.5)\% suggesting an even more advanced CHF population.

Despite the $\beta$ blocker and non- $\beta$ blocker groups being apparently comparable, patients had a significant advantage if they had been established on any dose of $\beta$ blocker; those not receiving a $\beta$ blocker at baseline were five times more likely to die $(31.7 \% \vee 5.9 \%, \mathrm{p}<0.001)$, despite treatment being commenced and optimised after referral. Treatment of CHF with an optimal dose of $\beta$ blocker has been shown to give the greatest increase in survival. ${ }^{6}$ The findings of this study complement these results, as patients taking the target dose of $\beta$ blocker were over 10 times less likely to die than those not taking a $\beta$ blocker $(31.7 \% \quad v \quad 3 \%$ mortality, $\mathrm{p}<0.0001$ ).

Also, patients in this study not treated with a $\beta$ blocker had a significantly higher concentration of NT-proBNP than those treated with a $\beta$ blocker. Treatment with, and increasing doses of, $\beta$ blockade were associated with a significantly lower baseline NT-proBNP concentration, which concurs well with NT-proBNP concentrations being a surrogate for improved prognosis in those individuals.

It is well recognised that the translation of clinical trial evidence is slow to filter out and become routine treatment in clinical practice. Today, in a population of patients with severe CHF referred largely by cardiologists, over 90\% were on an ACE inhibitor or ARB. However, in this same population, only two thirds were treated with $\beta$ blockersdrugs which have been conclusively shown to have prognostic benefit in severe $\mathrm{CHF}^{3}$ and should now be considered standard treatment.

This study confirms that patients with severe CHF not established on a $\beta$ blocker are at a significantly greater risk of death, and that not being on a $\beta$ blocker is an independent predictor of mortality. It thus extends the conclusions of the groundbreaking $\beta$ blocker trials in day-to-day clinical practice and stresses the importance of $\beta$ blocker treatment in the management of severe CHF.

\section{Authors' affiliations}

R S Gardner, Scottish Cardiopulmonary Transplant Unit, Glasgow Royal Infirmary, Glasgow, UK

W Martin, T A McDonagh, Department of Cardiology, University of

Glasgow, Glasgow, UK

R Carter, Department of Respiratory Medicine, Glasgow Royal Infirmary

Correspondence to: Dr Roy S Gardner, Scottish Cardiopulmonary Transplant Unit, Glasgow Royal Infirmary, Alexandra Parade, Glasgow G31 2ER, UK; rsgardner@doctors.org.uk 


\section{REFERENCES}

1 Deng MC, De MJ, Smits JM, et al. Effect of receiving a heart transplant: analysis of a national cohort entered on to a waiting list, stratified by heart failure severity. Comparative outcome and clinical profiles in transplantation (COCPIT) study group. BMJ 2000;321:540-5.

2 Cleland PJ, McGowan J, Clark A. The evidence for beta-blockers in heart failure. BMJ 1999;318:824-5

3 Packer M, Coats AJ, Fowler MB, et al. Effect of carvedilol on survival in severe chronic heart failure. N Engl J Med 2001;344:1651-8.
4 Witte K Thackray S, Clark AL, et al Clinical trials update: IMPROVEMENTHF, COPERNICUS, MUSTIC, ASPECT-II, APRICOT and HEART. Eur J Heart Failure 2000;2:455-60.

5 Waagstein F, Bristow M, Swedberg $\mathrm{K}$, et al. for the Metoprolol in Dilated Cardiomyopathy (MDC) Trial Study Group. Beneficial effects of metoprolol in idiopathic dilated cardiomyopathy. Lancet metoprolol in idiop

6 Bristow MR, Gilbert EM, Abraham WT, et al. Carvedilol produces doserelated improvements in left ventricular function and survival in subjects with chronic heart failure. Circulation 1996;94:2807-16.

\section{IMAGES IN CARDIOLOGY}

Levoatriocardinal vein without cardiac malformation and normal pulmonary venous return

A 5 year old boy was referred for evaluation of a heart murmur. Slight stenosis of the left pulmonary artery and an abnormal connection between the left pulmonary vein and the innominate vein was found on transthoracic echocardiography. MRI confirmed a dilated levoatriocardinal vein of $9 \mathrm{~mm}$ between the left superior pulmonary vein and the dilated innominate vein. The left pulmonary veins were normally connected to the left atrium (see fig). The left pulmonary artery was mildly compressed by the levoatriocardinal vein. Because of a left to right shunt $\left(Q_{p} / Q_{s} 1.4\right)$, the right sided heart was slightly enlarged but no other cardiovascular malformation was found. A 12-10 PDA Amplatzer device was used to completely occlude the levoatriocardinal vein. A levoatriocardinal vein is a pulmonary to systemic connection that provides a mechanism for decompression of the pulmonary venous blood, usually to bypass a severe left sided obstruction. Magnetic resonance imaging, particularly MR angiography, is the non-invasive procedure of choice to demonstrate this extracardiac anomaly. This case is original because the left heart is completely normal. Surgery or interventional cardiac catheterisation are both reasonable management options for this rare anomaly.

\author{
T Jaecklin \\ M Beghetti \\ D Didier \\ Maurice.Beghetti@hcuge.ch
}

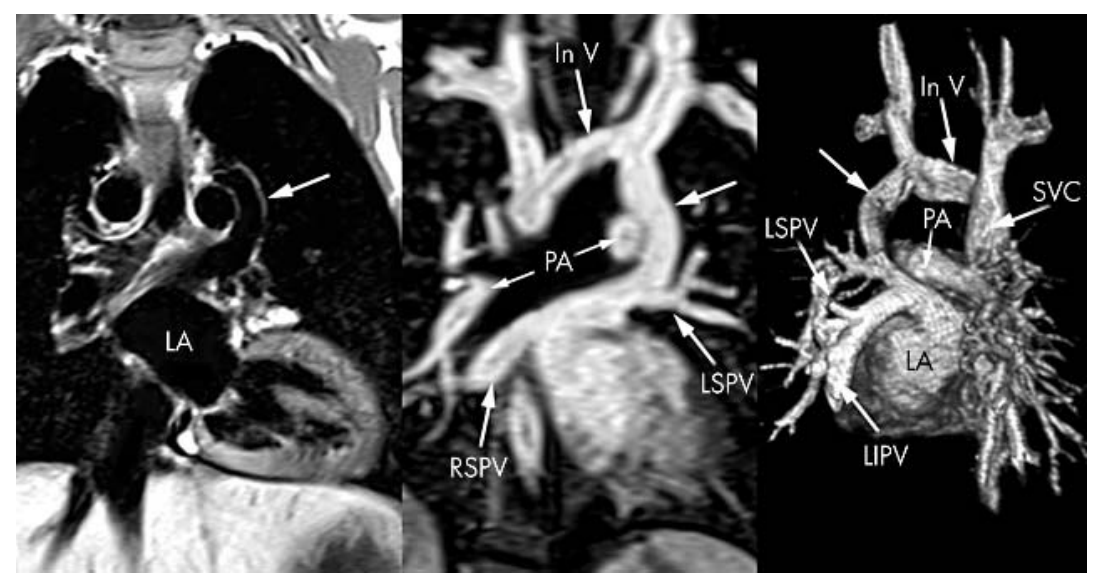

Coronal spin-echo magnetic resonance image (left panel), coronal mutliplanar reconstruction (centre panel), and posterior view of the volume rendering (right panel) of a gadolinium-enhanced three dimensional MR angiography. The levoatriocardinal vein (arrow), connecting the left superior pulmonary vein (LSPV) to the innominate vein (In V) is clearly demonstrated. Note the normal connection of all pulmonary veins to the left atrium (LA). $P A=$ pulmonary arteries; $S V C=$ superior vena cava; $R S P V=$ right superior pulmonary vein; $L I P V=$ left inferior pulmonary vein.

Pacing the left ventricle through the coronary sinus in a patient with a prosthetic tricuspid valve replacement
A
25 year old man with a history of intravenous drug abuse presented with a large tricuspid vegetation and evidence of uncontrolled infection. He underwent excision of the infected material and tricuspid valve replace- ment with a $33 \mathrm{~mm}$ bileaflet prosthesis.
After his operation he developed complete heart block requiring tempor- ary epicardial pacing and a pericardial effusion. The effusion was drained and a dual chamber pacemaker inserted using a lead in a posterior branch of the coronary sinus to pace the left ventricle.

Six months later he is well on warfarin with excellent pacing thresholds in the right atrium and left ventricle (both less than $0.65 \mathrm{~V}$ at $0.4 \mathrm{~ms}$ ).

The figure shows the relationship of the pacing lead (Medtronic 4193) to the tricuspid ring and to the posterior pericardial space delineated by the pericardial catheter.

S W Lord S C Clark stephen@lord31.fsnet.co.uk

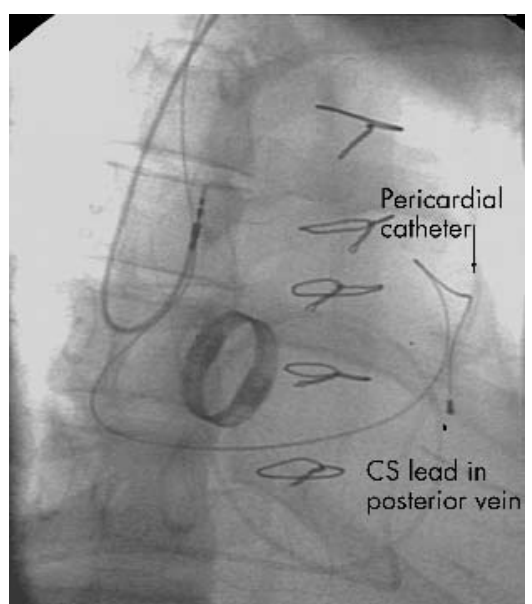

